\title{
Energetic, topological and electric field analyses of cation-cation nucleic acid interactions in Watson-Crick disposition
}

\author{
Ibon Alkorta, ${ }^{a},{ }^{*}$ Ignasi Mata, ${ }^{b, c}$ Elies Molins, ${ }^{\text {b }}$ Enrique Espinosa ${ }^{d,}{ }^{*}$
}

\footnotetext{
a Instituto de Química Médica (IQM-CSIC), Juan de la Cierva, 3, 28006-Madrid, Spain

${ }^{b}$ Institut de Ciència de Materials de Barcelona (ICMAB-CSIC), Campus UAB, 08193 Bellaterra, Spain

c Departament de Geologia, Universitat Autònoma de Barcelona, 08193 Bellaterra

d Université de Lorraine, CNRS, CRM2, Nancy, France
}

* Author to whom correspondence should be addressed: ibon@iam.csic.es, enrique.espinosa@univ-lorraine.fr

Supporting information for this article is available on the WWW under https://doi.org/10.1002/cphc.201800878

\section{Abstract}

A theoretical study of the effect of the diprotonation on the nucleic acid bases (A:U, A:T and G:C) in Watson-Crick conformation has been carried out by means of DFT computational methods in vacuum. In addition, the corresponding neutral and monoprotonated binary complexes have been considered. Most of the diprotonated species studied are stable, even though the binding energy is positive due to the overall repulsive electrostatic term. Local electrostatic attractive forces in the regions of hydrogen bonds (HBs) are responsible for equilibrium geometries, as shown by the 
electric field lines connecting the electrophilic and nucleophilic sites involved in the HB interactions. Secondary electrostatic effects also affect the assembling of the nucleic acid complexes in either neutral or cationic form. In particular, the electric field lines flowing from electrophilic sites in one base to nucleophilic sites in the other reinforce the linking between them. Hence, when the nucleophilic site concerns the free lone pair of the heteroatom involved in the HB interaction as acceptor, the HB distance shortens. However, if the free lone pair of the HB acceptor interacts with an electrophilic site in the same molecule, the HB distance elongates, weakening the $\mathrm{HB}$ interaction. The topological analysis of the electron density distribution in HB regions indicates that neutral, monoprotonated and diprotonated complexes show no differences in the nature of their HB's.

Keywords: Cation-Cation interaction, Electric field maps, DFT calculations, Nucleic acid binary complexes, Watson-Crick 


\section{Introduction}

Alterations of the properties of the nucleic acid bases are known to be the source of mutations. These modifications can be induced by chemical agents (intercalating agents, ${ }^{[1,2]}$ agents altering DNA structure, ${ }^{[3]}$ base analogs, like bromouracy|${ }^{[4]}$ ) or by electromagnetic ${ }^{[5,6]}$ and ionizing radiations. ${ }^{[7-9]}$

The importance of the nucleic acid bases and their dimers is reflected in the large number of experimental and theoretical studies. ${ }^{[10-13]}$ High level computational methods have been used to characterize the different tautomers of the isolated bases and the different dimers formed through hydrogen bonding or stacking interactions. Radical-cation DNA base pairs and proton transfer in excited state have been also modelled. ${ }^{[14]}$

The protonation state of the nucleobases is of main importance to define their three dimensional structure and activity. ${ }^{[15-18]}$ Charged nucleobases have been detected in RNA and DNA at neutral $\mathrm{pH}^{[19,20]}$ and the influence of the molecular environment on their specific pKa's values has been studied. ${ }^{[21]}$ Experimental charge density studies carried out with salts of protonated nucleobases have been shown that the molecules are involved in HB interactions in the crystal lattice. $^{[22][23]}$

Recently, several articles have pointed out the possibility that ionic molecules with the same sign can form stable minima in gas phase. ${ }^{[24-33]}$ The presence of such clusters in condensed media (in solution and in solid phases) is a well known fact. ${ }^{[34-38]}$ The term anti-electrostatic has been recently coined for this type of interactions ${ }^{[39,40]}$, even though some authors have challenged this term since it does not properly characterize the interaction between molecules with charge of the same sign. ${ }^{[41-43]}$

In the present article, the effect of mono- and di-protonation in the Watson-Crick (WC) binary complexes has been studied by means of DFT computational methods. The geometry of the binary complexes and their electronic properties in different states (neutral, mono and diprotonated) have been compared. The presence of positive binding energies with local minima in diprotonated complexes has been rationalized with the analysis of the electric field lines, which 
permit to understand how the electrostatic interactions evolve from neutral, to monoprotonated and diprotonated complexes. In addition, the topological analysis of the electron density has been applied in the HB regions to characterize the eventual differences that could appear in the assembling of neutral and charged complexes.

\section{Computational Methods}

Geometry optimizations for all the systems were calculated at the M06-2x/aug-cc-pVDZ[44, ${ }^{45]}$ computational level. This level of calculation has shown to be suitable to describe hydrogen bonded systems in neutral and charged systems ${ }^{[46-48]}$, as well as in the stacking of nucleobase dimers. ${ }^{[49-51]}$

In all geometry optimizations, frequency calculations were carried out at the same computational level. No imaginary frequencies were found in any case, confirming that the structures obtained correspond to energy minima. All geometry optimizations were performed with the Gaussian-09 program. ${ }^{[52]}$ The binding energies of the complexes have been calculated using Eq. 1:

$E b=E(A B)-E(A)-E(B) \quad$ Eq. 1

Where $E(A B)$ is the electronic energy of the complex and $E(A)$ and $E(B)$ are the energies of the corresponding isolated monomers in their minimum configuration. The relative energy of the complexes has been obtained with respect to the most stable isomeric complex.

The electron density of the complexes was analyzed within the Quantum Theory of Atoms in Molecules (QTAIM) methodology ${ }^{[33,54]}$ using the AIMAll program. ${ }^{[55]}$ Electric field lines have been calculated from the electrostatic potential, as calculated from AIMAll, and represented with the Matplotlib library. ${ }^{[56]}$

\section{Focused systems and nomenclature}

The nucleic acid binary complexes $(A: U, A: T$ and $G: C)$ in their Watson-Crick conformation have been protonated in the peripheral heteroatoms, laying in regions not involved in the hydrogen 
bonds to avoid steric clash between the hydrogen atoms (see Scheme 1). In order to simplify the calculations, the $\mathrm{R}$ and $\mathrm{R}^{\prime}$ groups that indicate the ribose and deoxyribose in the nucleic acids have been replaced by hydrogen atoms in our calculations.

Initially, the monoprotonated systems have been considered. The diprotonated complexes correspond to the monoprotonation in each of the two molecules involved in the complex. Thus, a total of 16 monoprotonated complexes ( 5 for $A: U$ and $A: T$, and 6 for $G: C$ ) and 20 diprotonated complexes ( 6 for $A: U$ and $A: T$, and 8 for $G: C$ ) have been initially taken into account.

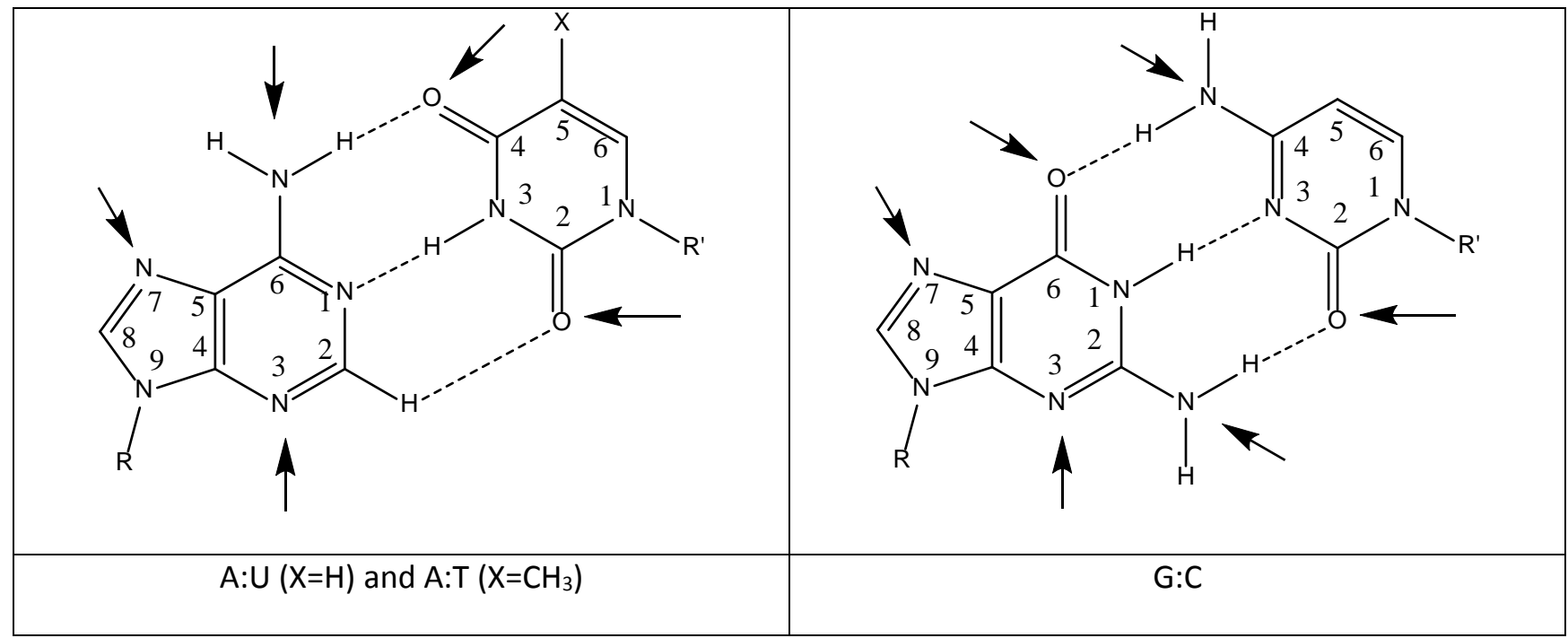

Scheme 1. The numbering used along the article is indicated. Arrows point the protonation sites at heteroatoms considered in the present article.

The nomenclature used in this article indicates in parenthesis the protonation site, using either the atomic number shown in Scheme 1 or the molecular group. Thus, $A(3): U$ corresponds to the $A: U$ complex protonated in position 3 of the adenine, and $A(7): U(O 2)$ indicates the $A: U$ complex protonated simultaneously in position 7 of the adenine and in the oxygen-2 of the Uracil.

\section{Results and Discussions}

\section{Energetic and geometric aspects}

Protonation of the isolated bases 
In order to compare the energetic values of the mono- and di-protonated binary complexes, the neutral bases have been protonated in the peripheral atoms not involved in the WC hydrogen bonding pattern. Thus, two protonated derivatives have been considered for $T, U$ and $C$, three for $A$ and four for $\mathrm{G}$. Their relative energies are listed in Table 1. In the pyridine bases $(T, U$ and $C)$ the most stable form corresponds to the protonation at one of the oxo groups ( $\mathrm{O} 4$ in $\mathrm{T}$ and $\mathrm{U}$, and $\mathrm{O} 2$ in C). In contrast, the most favorable protonated purines ( $A$ and $G$ ) correspond to the protonation at one of the nitrogen atoms of the bicyclic system, N3 and N7, respectively. In all cases, the protonation of the amino groups yield the less stable structures. These results are in agreement with the most stable protonated base obtained for G, T and U at MP4 computational level. ${ }^{[57]}$ In the case of $A$ and $C$, the most stable structures have not been considered here since they include atoms involved in the WC pairing.

Table 1. Relative energy Erel $(\mathrm{kJ} / \mathrm{mol})$ of the monoprotonated systems. The proton affinity $(\mathrm{kJ} / \mathrm{mol})$ of the most stable specie for each base is given in parenthesis.

\begin{tabular}{|l|c|l|c|l|c|}
\hline System & Erel(kJ/mol) & System & Erel(kJ/mol) & System & Erel(kJ/mol) \\
\hline $\mathrm{A}(3)$ & $\begin{array}{c}0.0 \\
(958.0)\end{array}$ & $\mathrm{T}(\mathrm{O} 4)$ & $\begin{array}{c}0.0 \\
(892.8)\end{array}$ & $\mathrm{U}(\mathrm{O} 4)$ & $\begin{array}{c}0.0 \\
(886.1)\end{array}$ \\
\hline $\mathrm{A}(7)$ & 30.2 & $\mathrm{~T}(\mathrm{O} 2)$ & 33.5 & $\mathrm{U}(\mathrm{O} 2)$ & 43.0 \\
\hline $\mathrm{A}\left(\mathrm{NH}_{2}\right)$ & 87.2 & & & & \\
\hline & & & & & \\
\hline $\mathrm{G}(7)$ & $\begin{array}{c}0.0 \\
(976.6)\end{array}$ & $\mathrm{C}(\mathrm{O} 2)$ & $\begin{array}{c}0.0 \\
(952.2)\end{array}$ & & \\
\hline $\mathrm{G}(\mathrm{O} 6)$ & 16.5 & $\mathrm{C}\left(\mathrm{NH}_{2}\right)$ & 110.3 & & \\
\hline $\mathrm{G}(3)$ & 68.9 & & & & \\
\hline $\mathrm{G}\left(\mathrm{NH}_{2}\right)$ & 162.1 & & & & \\
\hline
\end{tabular}

Neutral complexes.

The QTAIM molecular graph of the neutral $A: U$ and $G: C$ complexes are gathered in Fig. 1 . The geometry and the electronic energy of these systems are gathered in the Table S1 of the Supplementary Information material. Since the A:T and A:U complexes are similar, the former have not been included in the main text but can be found in the Supporting Information material (Table S1). The calculated binding energies of the binary complexes are $-63.2,-64.0$ and $-118.7 \mathrm{~kJ} / \mathrm{mol}$ for A:T, A:U and G:C, respectively. These results are in good agreement with those previously reported in the literature at MP2 level (-69 and -109 $\mathrm{kJ} / \mathrm{mol}$ for $\mathrm{A}: \mathrm{T}$ and $\mathrm{G}: \mathrm{C})^{[58,59]}$ 


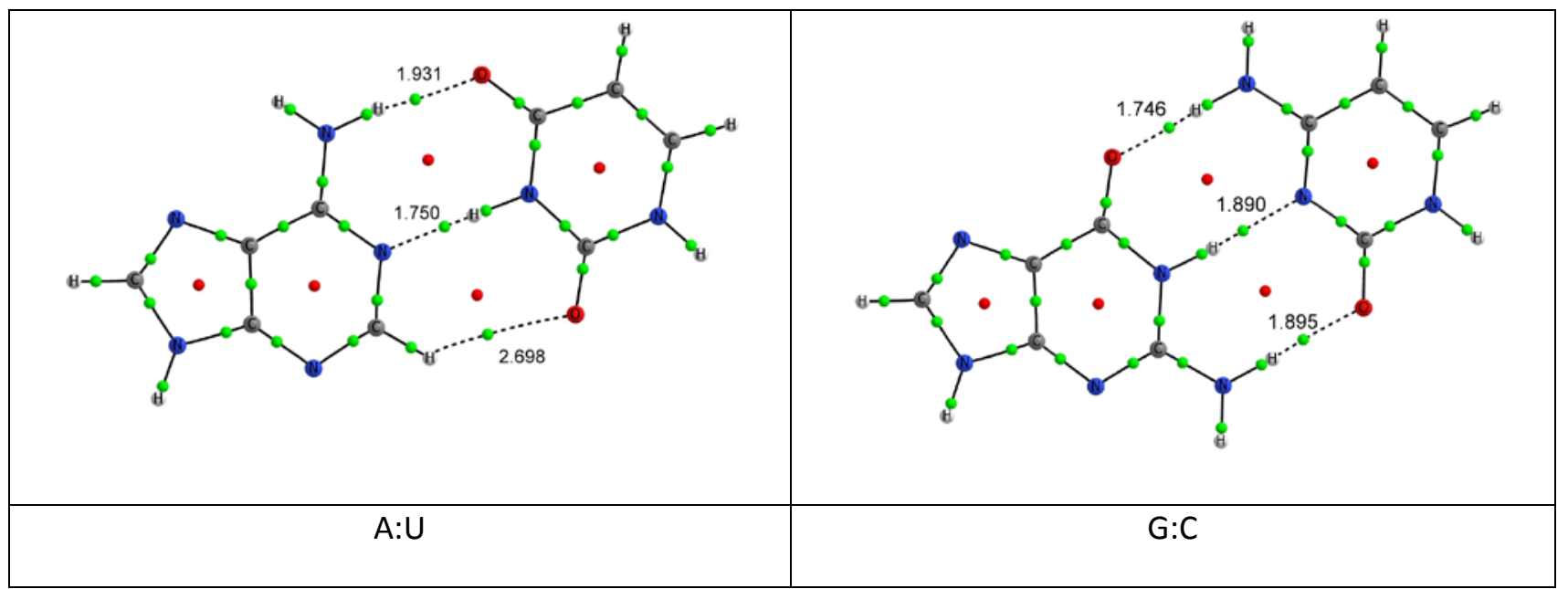

Fig. 1. QTAIM molecular graph of the neutral A:U and G:C complexes. Green and red dots indicate the position of the bond and ring critical points, respectively. Interatomic distances between atoms involved in HB's are indicated in $\AA$.

\section{Monoprotonated complexes}

All the initial monoprotonated complexes provide a bonded minimum (Fig. 2 and Table S2). However, the protonation of the $\mathrm{NH}_{2}$ group of $\mathrm{A}, \mathrm{G}$ and $\mathrm{C}$ produces an spontaneous proton transfer from these molecules, with neutralization of the $\mathrm{NH}_{2}$ group, towards the oxygen atom of the other molecule involved in the $\mathrm{HB}\left[\mathrm{A}\left(\mathrm{NH}_{2}\right): \mathrm{U}, \mathrm{G}\left(\mathrm{NH}_{2}\right): \mathrm{C}\right.$, and $\left.\mathrm{G}: \mathrm{C}\left(\mathrm{NH}_{2}\right)\right]$. Something similar happens in the protonation of the oxygen atoms in position 2 and 4 of $U$ and $T[A: U / T(O 2)$ and $A: U / T(O 4)]$, that yield the proton transfer of the $\mathrm{N}-\mathrm{H}$ group in position 3 of $\mathrm{U} / \mathrm{T}$ towards the $\mathrm{N} 1$ of adenine, leaving the $\mathrm{U} / \mathrm{T}$ molecule neutral and $\mathrm{A}$ with a positive charge. In addition, the hydrogen bonding pattern change due to the shift of one molecule with respect to the other one in $\mathrm{A}: \mathrm{U}(\mathrm{O} 4)$ and $\mathrm{G}: \mathrm{C}\left(\mathrm{NH}_{2}\right)$ complexes, as can be seen in Fig. 2 to better accommodate the HB acceptor of the neutral molecule and the HB donors of the protonated one. These structures resemble a wobble base pair. ${ }^{[60]}$

All the monoprotonated binary complexes are more stable than the corresponding neutral ones, except the $\mathrm{G}: \mathrm{C}(\mathrm{O} 2)$ complex that is less stable than the $\mathrm{G}: \mathrm{C}$ one $(-85 \mathrm{vs} .-109 \mathrm{~kJ} / \mathrm{mol}$, respectively) (Table 2). The binding energies range between -80 and $-175 \mathrm{~kJ} / \mathrm{mol}$ for protonated A:T and A:U complexes, and between -85 and $-296 \mathrm{~kJ} / \mathrm{mol}$ for protonated G:C ones. The inclusion of the zero point energy (ZPE) correction reduces the binding energies about $5 \mathrm{~kJ} / \mathrm{mol}$ (Table S3).

The most stable protonated binary complexes are $A: T(O 4), A: U(O 4)$ and $G(7): C . G(7): C$ corresponds to the protonation on the most basic center of the isolated $\mathrm{G}$ and $\mathrm{C}$ molecules. In the case of $\mathrm{A}, \mathrm{T}$ and $\mathrm{U}$, the 
most basic center corresponds to $A(3)$. However, the $A(3): T$ and $A(3): U$ binary complexes present two of the smallest binding energies in absolute terms $(-82$ and $-81 \mathrm{~kJ} / \mathrm{mol})$, therefore favoring the $A: T(O 4), A: U(04)$ complexes with binding energies of -169 and $-174 \mathrm{~kJ} / \mathrm{mol}$.

Table 2. Binding $\mathrm{Eb}(\mathrm{kJ} / \mathrm{mol})$ and relative $\mathrm{Erel}(\mathrm{kJ} / \mathrm{mol})$ energies of the monoprotonated binary complexes with respect to the most stable isomer for each pair (AT, AU, and $G C)$.

\begin{tabular}{|c|c|c|}
\hline System & $\mathrm{Eb}(\mathrm{kJ} / \mathrm{mol})$ & $\operatorname{Erel}(\mathrm{kJ} / \mathrm{mol})$ \\
\hline$A(3): T$ & -81.9 & 21.9 \\
\hline$A(7): T$ & -80.4 & 53.6 \\
\hline $\mathrm{A}\left(\mathrm{NH}_{2}\right): \mathrm{T}^{\mathrm{a}}$ & -145.1 & 45.8 \\
\hline $\mathrm{A}: \mathrm{T}(\mathrm{O} 2)^{\mathrm{b}}$ & -166.4 & 36.0 \\
\hline $\mathrm{A}: \mathrm{T}(\mathrm{O} 4)^{\mathrm{b}}$ & -169.0 & 0.0 \\
\hline$A(3): U$ & -80.8 & 20.8 \\
\hline$A(7): U$ & -80.2 & 51.6 \\
\hline$A\left(N_{2}\right): U^{a}$ & -142.6 & 46.2 \\
\hline$A: U(O 2)^{b}$ & -175.1 & 41.5 \\
\hline $\mathrm{A}: \mathrm{U}(04)$ & -173.6 & 0.0 \\
\hline $\mathrm{G}: \mathrm{C}\left(\mathrm{NH}_{2}\right)^{\mathrm{a}}$ & -296.0 & 0.4 \\
\hline $\mathrm{G}: \mathrm{C}(\mathrm{O} 2)$ & -85.3 & 100.8 \\
\hline$G(7): C$ & -161.8 & 0.0 \\
\hline$G(3): C$ & -201.2 & 29.5 \\
\hline $\mathrm{G}\left(\mathrm{NH}_{2}\right): \mathrm{C}^{\mathrm{a}}$ & -273.2 & 50.7 \\
\hline $\mathrm{G}(06): C$ & -156.8 & 21.5 \\
\hline
\end{tabular}

${ }^{a}$ Proton transfer from the protonated $\mathrm{NH}_{2}$ group towards the $\mathrm{O}$ atom of the other molecule involved in the HB. Eb has been calculated using the protonated amine as reference.

${ }^{b}$ Proton transfer from N3 of the U/T molecule towards N1 of the A molecule. Eb has been calculated using the protonated $\mathrm{U} / \mathrm{T}$ molecule on the corresponding oxygen atom.

The comparison of the interatomic distances between the neutral and the protonated $\mathrm{G}: \mathrm{C}$ complexes, where the HB pattern is unaltered, shows that protonation on the $G$ moiety $[G(7): C, G(3): C$ and $\mathrm{G}(06): \mathrm{C}]$ produces an elongation of the $\mathrm{O}(6) \ldots \mathrm{HN}(4) \mathrm{HB}$ and a shortening of the $\mathrm{N}(1) \mathrm{H} \cdots \mathrm{N}(3)$ and $\mathrm{N}(3) \mathrm{H} \cdots \mathrm{O}(2)$ HBs. The effects are opposite when the protonation happens on the $C$ molecule $[G: C(O 2)]$. In the $A: U$ complexes, the protonation on the $A$ monomer $[A(3): U$ and $A(7): U]$ shortens the $N(6)-H \cdots O(4)$ distance and elongate the $\mathrm{N}(1) \cdots \mathrm{H}-\mathrm{N}(3)$ one. 


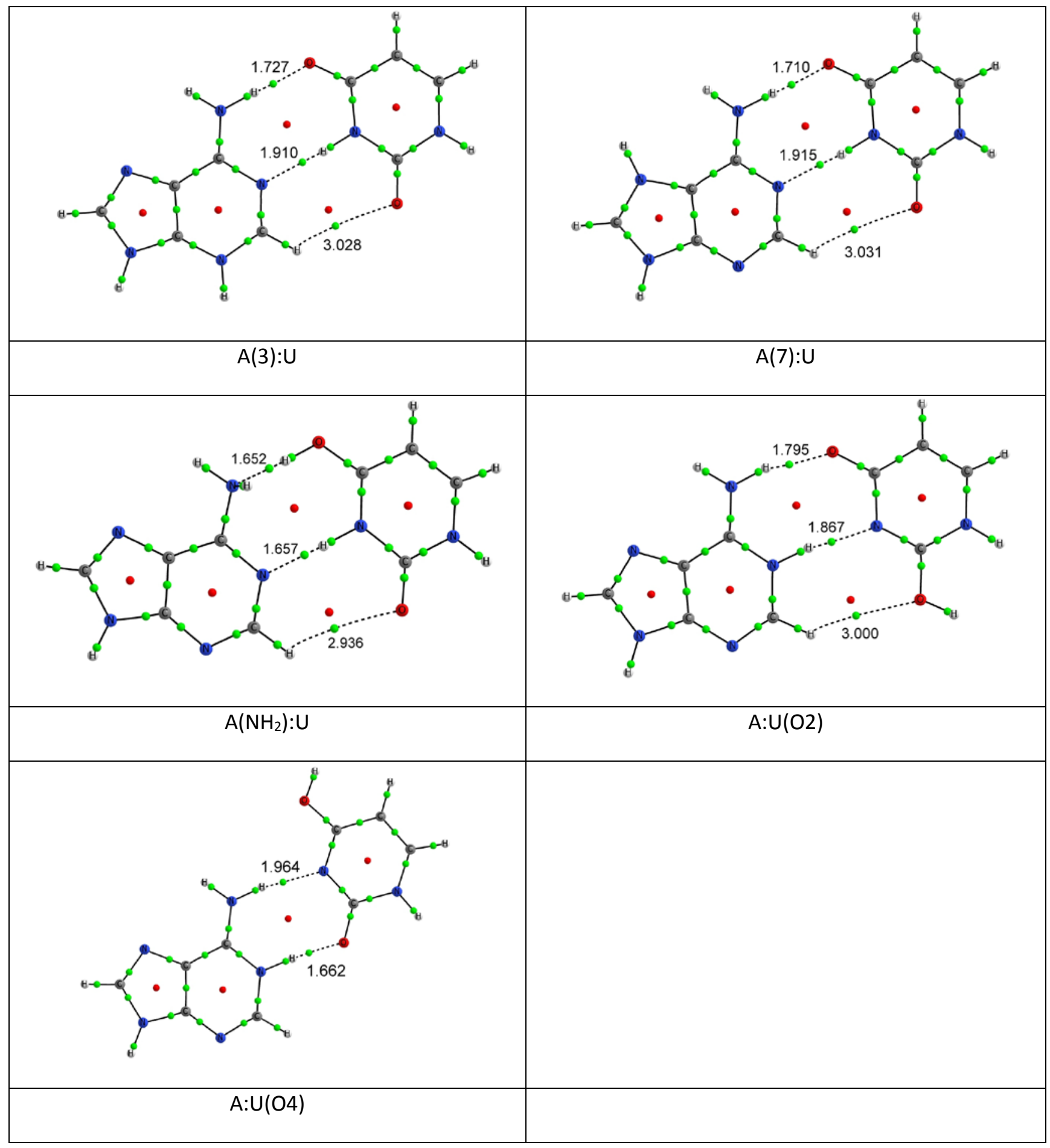




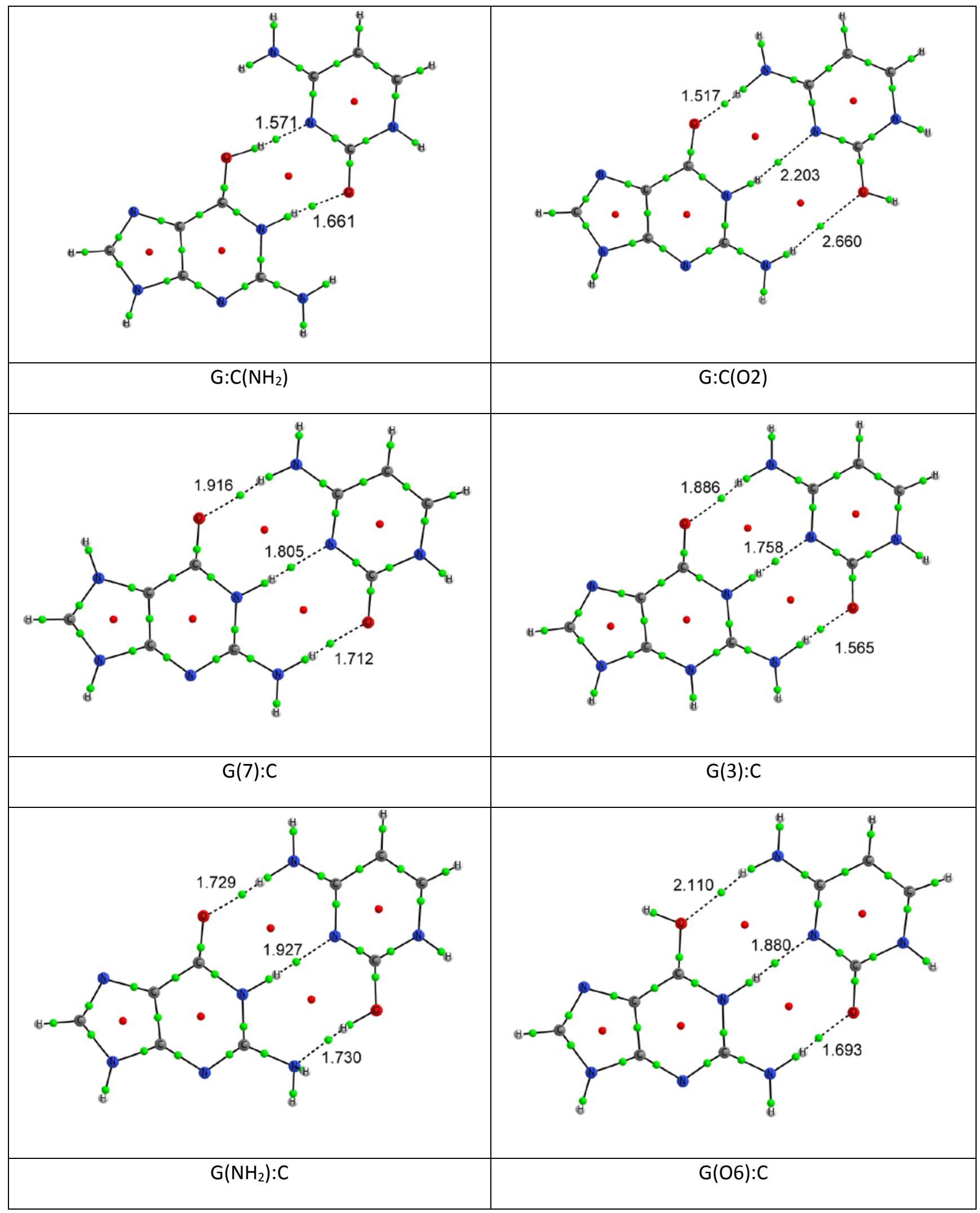

Fig. 2. QTAIM molecular graph of the monoprotonated complexes of $A: U$ and $G: C$. Green and red dots indicate the position of the bond and ring critical points, respectively. HB distances between base pairs are shown in $\AA$. 


\section{Diprotonated complexes.}

Five minima for diprotonated $\mathrm{A}: \mathrm{U}$ and seven for diprotonated $\mathrm{G}: \mathrm{C}$ complexes have been located starting from 6 and 8 different molecular structures, respectively (Fig. 3 and Table S4). $A\left(\mathrm{NH}_{2}\right): \mathrm{U}(\mathrm{O} 4)$ and $\mathrm{G}\left(\mathrm{NH}_{2}\right): \mathrm{C}\left(\mathrm{NH}_{2}\right)$ are missing structures which tend to dissociate. In all the minima found, the hydrogen bonding pattern of the neutral complexes is maintained, save in the $G(06): C\left(N_{2}\right)$ complex where the $C$ molecule is shifted and only the oxo group of $C$ is involved in the HB with $G$.

The most stable diprotonated structures are $A(3): U(O 4), A(3): T(O 4)$ and $G(7): C(O 2)$, which are generated from the most stable monoprotonated ones (Table 3). For instance, $A: U(O 4)$ is the most stable monoprotonated structure for these pair of bases, whereas $A(3): T$ is the most stable structure protonated on A. Similarly, $G(7): C$ is the most stable monoprotonated structure and $\mathrm{C}$ is only stable when protonated at $\mathrm{O} 2$ since $\mathrm{G}: \mathrm{C}\left(\mathrm{NH}_{2}\right)$ evolves with proton transfer.

In all cases, as a consequence of the overall repulsion between the monomers, the binding energies are positive. The Eb values range between 99 and $140 \mathrm{~kJ} / \mathrm{mol}$ for A:T and A:U diprotonated complexes, and between 31 and $161 \mathrm{~kJ} / \mathrm{mol}$ for the G:C ones. The HB distances increase when compared to those of the neutral complexes, except for $\mathrm{N}(6)-\mathrm{H} \cdots \mathrm{O}$ in $\mathrm{A}(3): \mathrm{U}(\mathrm{O} 2)$ and $\mathrm{A}(7): \mathrm{O}(2)$, and $\mathrm{O}(6) \cdots \mathrm{H}-\mathrm{N}(4)$ in $\mathrm{G}(3): \mathrm{C}\left(\mathrm{NH}_{2}\right)$ and $\mathrm{G}(7): \mathrm{C}\left(\mathrm{NH}_{2}\right)$ complexes. As in the case of the monoprotonated systems, the inclusion of the ZPE correction has little effect on the binding and relative energies (Table S5)

Table 3. Binding $\mathrm{Eb}(\mathrm{kJ} / \mathrm{mol})$ and relative $\mathrm{Erel}(\mathrm{kJ} / \mathrm{mol})$ energies of the diprotonated binary complexes with respect to the most stable isomer for each pair (AT, $A U$, and GC).

\begin{tabular}{|l|c|c|}
\hline System & $E b(\mathrm{~kJ} / \mathrm{mol})$ & Erel(kJ/mol) \\
\hline$A(3): T(O 2)$ & 128.8 & 26.1 \\
\hline$A(3): T(O 4)$ & 136.1 & 0.0 \\
\hline$A(7): T(O 2)$ & 98.8 & 26.4 \\
\hline$A(7): T(O 4)$ & 120.2 & 14.3 \\
\hline$A\left(\mathrm{NH}_{2}\right): \mathrm{T}(\mathrm{O} 2)$ & 110.5 & 95.0 \\
\hline & & \\
\hline$A(3): U(O 2)$ & 131.5 & 34.0 \\
\hline$A(3): U(O 4)$ & 140.5 & 0.0 \\
\hline$A(7): U(O 2)$ & 99.4 & 32.2 \\
\hline$A(7): U(O 4)$ & 122.8 & 12.5 \\
\hline
\end{tabular}




\begin{tabular}{|l|c|c|}
\hline$A\left(\mathrm{NH}_{2}\right): \mathrm{U}(\mathrm{O} 2)$ & 112.9 & 102.6 \\
\hline $\mathrm{G}(3): \mathrm{C}\left(\mathrm{NH}_{2}\right)$ & & \\
\hline $\mathrm{G}(3): \mathrm{C}(\mathrm{O} 2)$ & 30.6 & 98.6 \\
\hline $\mathrm{G}(7): \mathrm{C}\left(\mathrm{NH}_{2}\right)$ & 115.5 & 73.2 \\
\hline $\mathrm{G}(7): \mathrm{C}(\mathrm{O} 2)$ & 46.7 & 45.7 \\
\hline $\mathrm{G}\left(\mathrm{NH}_{2}\right): \mathrm{C}\left(\mathrm{O}_{2}\right)$ & 111.2 & 0.0 \\
\hline$G(\mathrm{O}): \mathrm{C}\left(\mathrm{NH}_{2}\right)$ & 118.6 & 169.5 \\
\hline$G(\mathrm{O} 6): \mathrm{C}\left(\mathrm{O}_{2}\right)$ & 102.9 & 118.4 \\
\hline
\end{tabular}

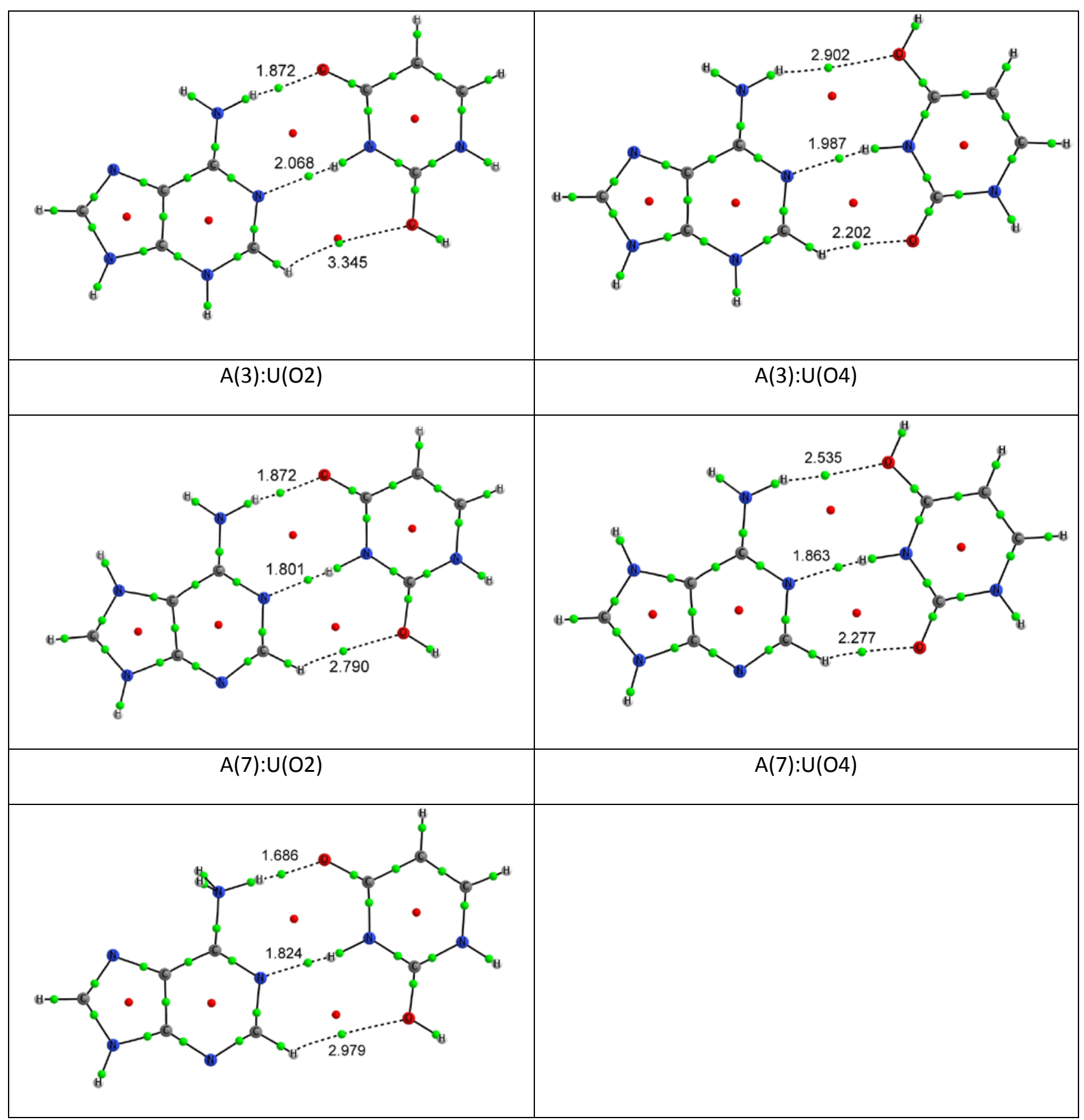




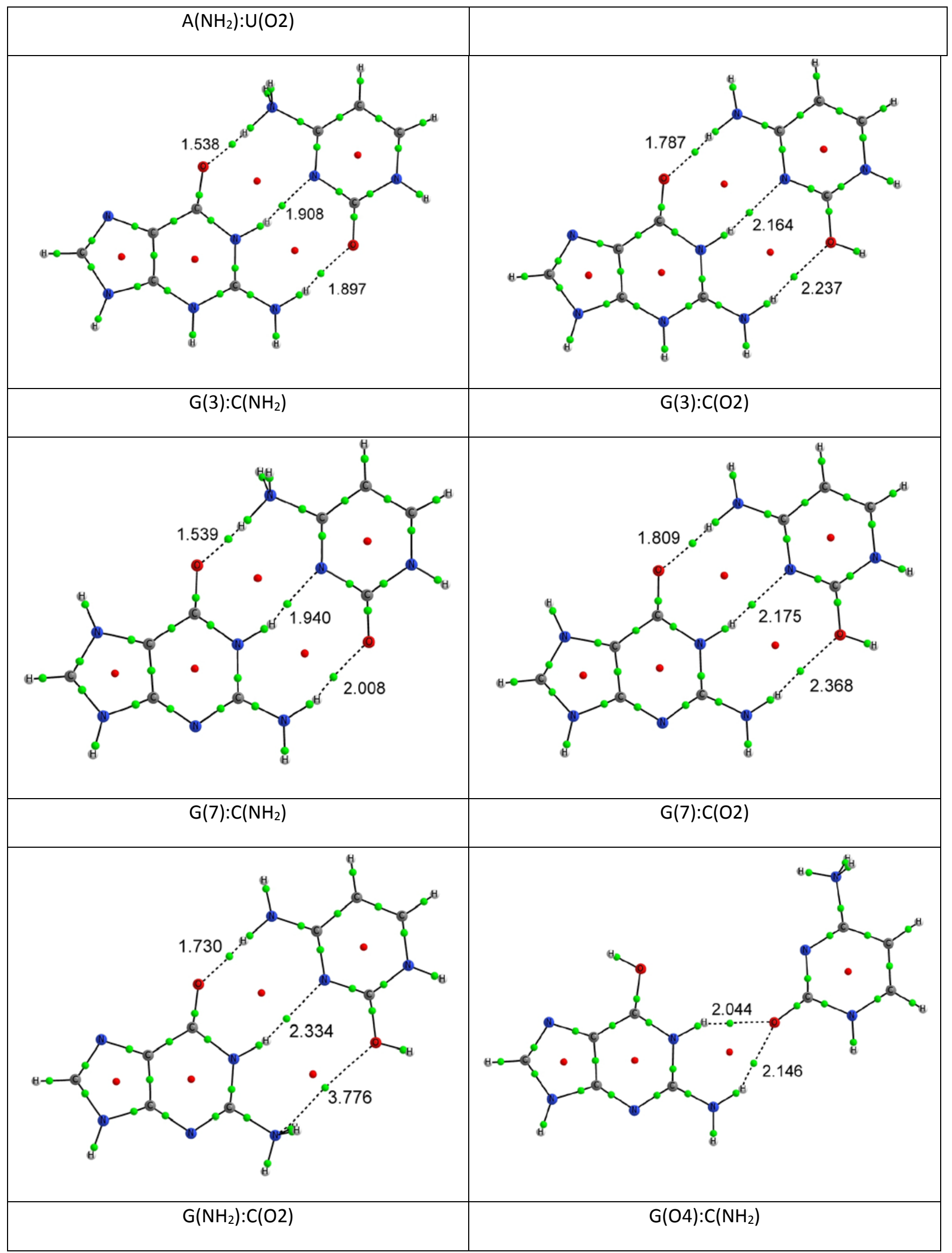




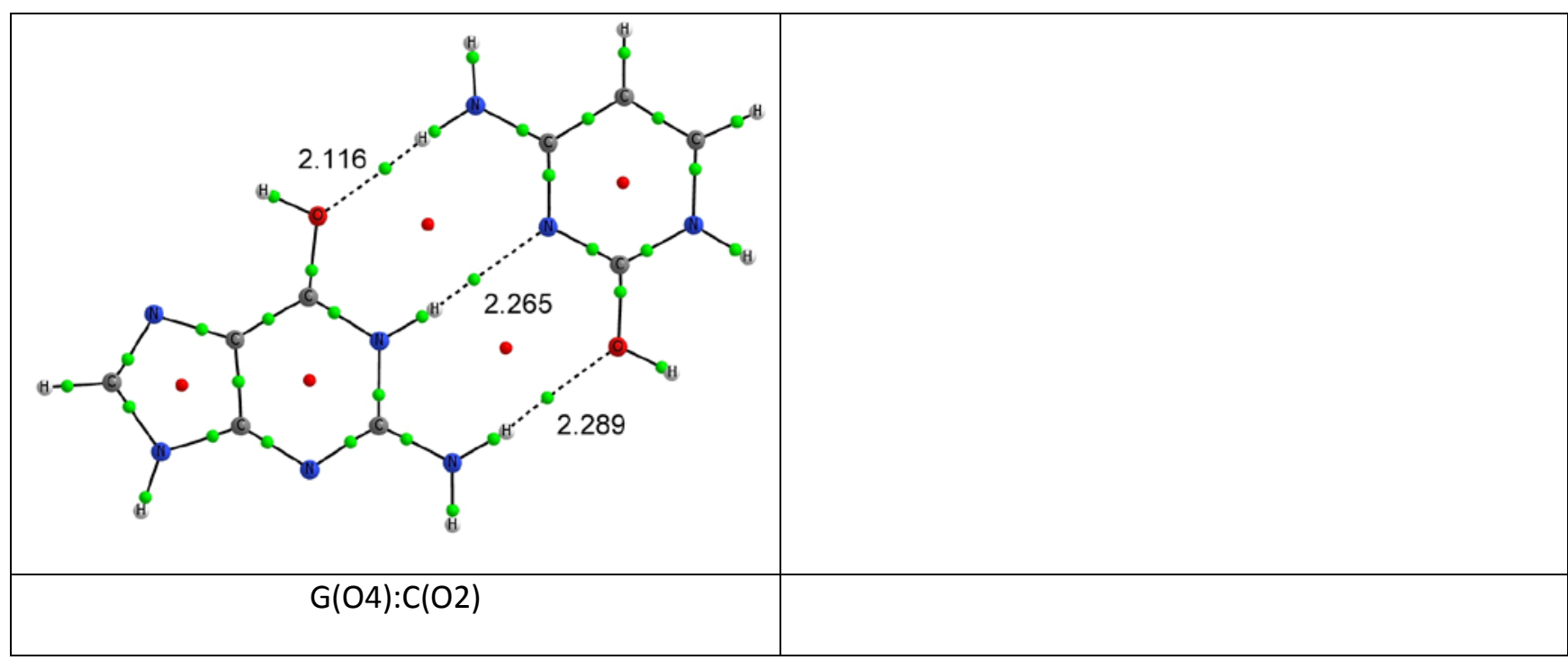

Fig. 3. QTAIM molecular graph of the diprotonated complexes of A:U and G:C . Green and red dots indicate the position of the bond and ring critical points, respectively. The interatomic distance of the atoms involved in the HB's are indicated.

\section{Electronic aspects: Topological properties at bond critical points}

The QTAIM molecular graphs of the complexes, which show the location of the intramolecular and intermolecular bond and ring critical points, as well as the bond paths, are gathered in Figures 1-3. The $\mathrm{N} \cdots \mathrm{H}$ and $\mathrm{O} \cdots \mathrm{H}$ intermolecular BCP's have been analyzed separately. A total of 38 and 66 BCP's have been respectively found for these intermolecular interactions, displaying a range of distances of 1.57-2.33 $\AA$ for $\mathrm{N} \cdots \mathrm{H}$ and of 1.52-3.35 for O $\cdots \mathrm{H}$ HB's. The plots of the topological and energetic properties at BCP's (electron density $\rho_{B C P}$, Laplacian of the electron density $\nabla^{2} \rho_{B C P}$, three main curvatures $\left|\lambda 1_{B C P}+\lambda 2_{B C P}\right|$ and $\lambda 3_{B C P}$, local potential, kinetic, and total energy densities $V_{B C P}, G_{B C P}, H_{B C P}=G_{B C P}+V_{B C P}$, and $\left.\left|V_{B C P}\right| / G_{B C P}\right)$ against the interatomic distance of these interactions are given in Fig. 4(a-h, respectively) for the $\mathrm{N} \cdots \mathrm{H}$ interactions and in Fig. S1 for the $\mathrm{O} \cdots \mathrm{H}$ ones. The data do not show any significant influence of the charge of the complexes on the behaviors that these properties exhibit against the internuclear distances, indicating that neutral, monoprotonated and diprotonated complexes can be considered together within the same data set. This result confirms our previous study pointing that there is no difference in the nature of HBs involved in either neutral or charged complexes. ${ }^{[30]}$ Hence, for all the topological and energetic properties [except for $\nabla^{2} \rho_{\mathrm{BCP}}$ (Fig. 4b) and $\mathrm{H}_{\mathrm{BCP}}$ (Fig. 4g), which exhibit particular behaviors], data have been fitted with single exponential curves $\left(R^{2}>0.99\right)$, even if small deviations are observed for some of them around $1.90 \AA$ for $N \cdots H$ and $2.2 \AA$ for $\mathrm{O} \cdots \mathrm{H}$. They are in agreement with previous reports ${ }^{[61]}$ and in line with the dependencies found for a

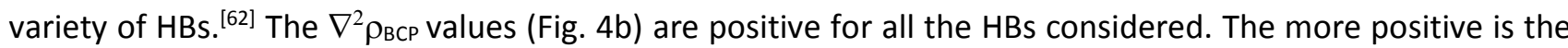
$\nabla^{2} \rho_{\mathrm{BCP}}$ magnitude the more depleted is the electron distribution, while the reverse applies for less positive 
magnitudes. $\nabla^{2} \rho_{\text {BCP }}$ values increase exponentially from longer distances as the intermolecular distance shortens, indicating the increase of charge depletion in a pure closed-shell interaction. Indeed, for this type of interaction, the increase of the electronic charge in the internuclear region (as observed from the plot of $\left.\rho_{\mathrm{BCP}}\right)$ that accompanies the strengthening of the interaction is stabilized by the concomitant increase of its depletion. From longer distances, the exponential dependence of the charge depletion is observed up to approximately $1.90 \AA$ for $\mathrm{N} \cdots \mathrm{H}$ and $1.75 \AA$ for $\mathrm{O} \cdots \mathrm{H}$, from where the dependence progressively stops. For shorter distances, the depletion of charge monotonically reduces. The features observed on $\nabla^{2} \rho_{\mathrm{BCP}}$ are the straightforward consequence of the balance between the potential $V_{B C P}$ (Fig. 4e) and the kinetic $G_{B C P}$ energy densities (Fig. 4f), which controls the behavior of $\nabla^{2} \rho_{B C P}$ from the local form of the virial theorem. ${ }^{[53,63]}$ Hence, from larger distances and paralleling the $\nabla^{2} \rho_{B C P}$ increase, the values of $H_{B C P}$ (Fig. 4g) are positive and monotonically increase up to a small maximum, which corresponds to the greatest positive difference between $G_{B C P}$ and $\left|V_{B C P}\right|$. This local maximum is observed at approximately 1.95 for $\mathrm{N} \cdots \mathrm{H}$ and $1.85 \AA$ for $\mathrm{O} \cdots \mathrm{H}$. For shorter distances, a faster increase of $\left|\mathrm{V}_{\mathrm{BCP}}\right|$ than of $\mathrm{G}_{\mathrm{BCP}}$ occurs, leading to the starting decrease of the $H_{B C P}$ magnitude and to the progressive stopping of the $\nabla^{2} \rho_{B C P}$ increase. Then, for distances shorter than approximately $1.85 \AA$ for $\mathrm{H} \cdots \mathrm{N}$ HBs and $1.70 \AA$ for $\mathrm{H} \cdots \mathrm{O}$ HBs, a first decrease of charge depletion is observed in the interactions $\left(\nabla^{2} \rho_{\mathrm{BCP}}>0 \downarrow\right)$, following the increase of the ratio between the energetic components $\left|\mathrm{V}_{\mathrm{BCP}}\right| / \mathrm{G}_{\mathrm{BCP}}$ (Fig. 4h) $>1\left(\mathrm{H}_{\mathrm{BCP}}<0\right)$. In a previous work, ${ }^{44}$ pure closed-shell and intermediate closed-shell interactions have been respectively identified in regions where $V_{B C P} \mid / G_{B C P}<1$ (region I) and $2<V_{B C P} \mid / G_{B C P}<1$ (region II), the latter pointing an incipient covalent character that starts to take place in the interaction even if still $\nabla^{2} \rho_{B C P}>0$. Interactions displaying local concentration of charge $\left(\nabla^{2} \rho_{B C P}<0,\left|V_{B C P}\right| / G_{B C P}>2\right.$, region III) correspond to a shared bonding or covalent interaction. For HB's, this trend can be only observed with very strong interactions, ${ }^{[61]}$ which are not concerned in this work.

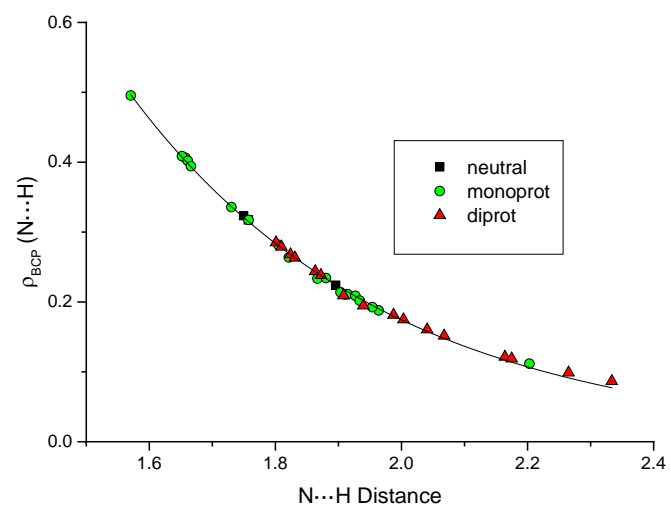

a)

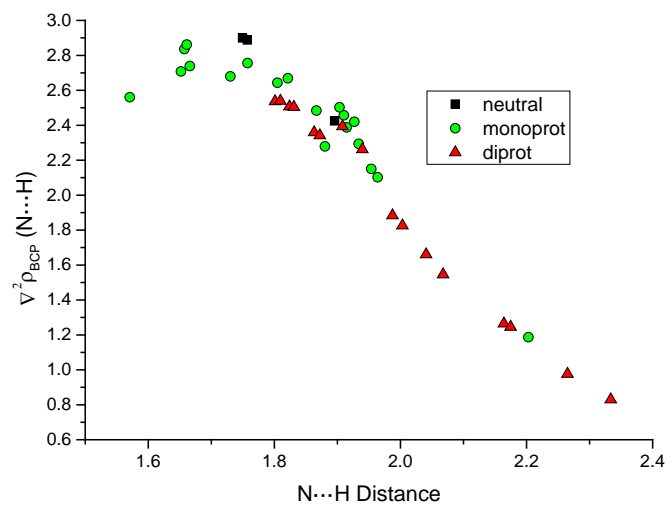

b) 


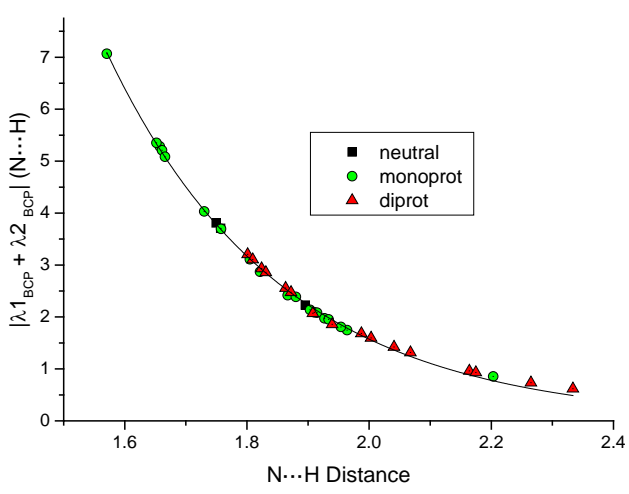

c)

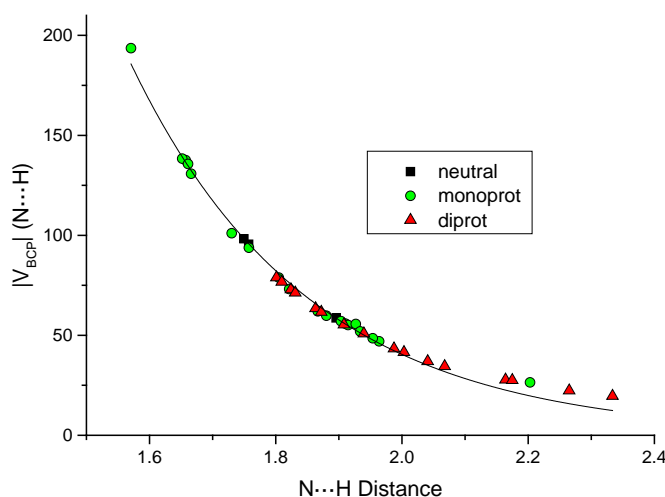

e)

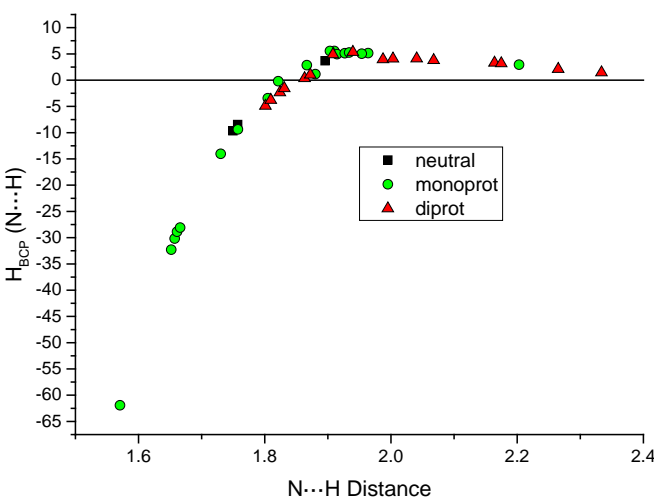

g)

Figure 4. Topological and energetic properties at BCPs vs. internuclear $\mathrm{N} \cdots \mathrm{H}$ distances. Fittings have been carried out with exponential functions, involving all the neutral, monoprotonated and diprotonated complexes analyzed in this study. Units are: distance in $\AA$, $\rho_{B C P}$ in e $/ \AA^{3}, \lambda i_{B C P}(i=1,2,3)$ and $\nabla^{2} \rho_{B C P}$ in e/ $/ \AA^{5}$, energy densities $G_{B C P}, V_{B C P}$ and $H_{B C P}$ in $\mathrm{kJ} / \mathrm{mol} / \mathrm{a}_{0}^{3}$, and $\left|V_{B C P}\right| / G_{B C P}$ is dimensionless.

\section{Electrostatic analysis from electric field lines}

\section{General remarks}


The electric field lines of neutral, most stable mono and diprotonated binary complexes that retain the WC configuration are shown in Fig. $5[A: U, A(3): U, A(3): U(O 4), G: C, G(7): C$, and $G(7): C(O 2)$ complexes]. In each plot, the volumes occupied by the uracil or cytosine, on one hand, and by the adenine or guanine, on the other, are respectively indicated as dark and light shaded regions, and they have been calculated from the topology of $\rho(r)$. The volumes are bounded by the isosurface $\rho(r)=0.007$ e $\AA^{-3}(\sim 0.001$ a.u. $)$, which corresponds approximately to the van der Waals surface. ${ }^{[64]}$ Electric field lines are starting at electrophilic sites (denoted by $(3,+3)$ critical points in the topology of the electrostatic potential $\varphi$ ) and ending at nucleophilic sites (denoted by $(3,-3)$ critical points in the same topology). ${ }^{[65]}$ They are force lines linking molecular regions by attractive electrostatic forces that are at the origin of molecular assembling. Each field line is hence monitoring the way the attractive electrostatic interaction between a pair of electrophilic/nucleophilic sites takes place through the space. Particularly interesting is to observe their disposition in the intermolecular regions, because it permits to understand how molecules link in their assembling.

For each pair of bases shown in Fig. 5 (neutral, monoprotonated and diprotonated complexes), the electric field lines are very similar in the intermolecular HB regions, where the systems conserve most of the topographical disposition and density of electric field lines. It is especially interesting to note that HB regions recovered by the field lines starting in one molecule corresponds to the volume occupied by the other molecule. This intermolecular region, which corresponds to the intersection of the basins generated from the topologies of $\rho$ and the electrostatic potential $\varphi$ in the $\mathrm{HBs},{ }^{[66]}$ is called electrostatic attraction region (EAR) as the molecules attract to each other thanks to the electric field lines linking their electrophilic and nucleophilic regions. ${ }^{[26,28]}$ In addition to the EAR in the HBs, some electric field lines flowing between the molecules are also linking other of their electrophilic and nucleophilic sites, adding further attractive electrostatic contributions in the complexes. This is observed in Fig. 5, where field lines connect some nitrogen and/or hydrogen nuclei (electrophilic sites) to oxygen free lone pairs (nucleophilic sites). The electric field lines linking the molecules through the corresponding EARs are not significantly modified on going from neutral to monoprotonated and diprotonated complexes. Consequently, the existence of local attractive electrostatic forces in the diprotonated complexes are able to induce restoring forces that locally overcome the overall repulsion of the molecular net charges, yielding a local minimum in the interaction energy. Similar conclusions have been reached in the complexes formed by oxoacids ${ }^{[29]}$ and with other cationic and anionic complexes ${ }^{21}$.

On the other hand, the electric field lines significantly differ in the periphery of neutral and charged complexes. Thus, while field lines are flowing between parts of the complex in the neutral systems, some of them do not connect anymore the molecules in the monoprotonated complexes, and almost all of them are 
pointing outwards in the diprotonated systems. These trends are typically found in the topography of electric field lines in neutral molecules and cations, respectively. ${ }^{[65]}$ As expected, in molecular regions closer to the protonated sites, electric field lines are very different between the three kinds of complexes, leading to changes in their electrostatic influence on other parts of these systems. Hence, as a main consequence of mono- and di-protonation, electric field lines flowing from hydrogen nuclei towards oxygen free lone pairs in neutral complexes (out of the three WC HBs linking both molecules) disappear in charged systems.

Features similar than these pointed with complexes of Fig. 5 are also found with the other complexes analyzed in this study (see Fig. S2-3 in S.I. material).

\section{Neutral complexes}

In the neutral complexes, protonation centers exhibit electric field lines that start in the electrophilic sites of the complex and orient towards the external molecular regions. The electric field lines are thus ending at the free lone pairs (nucleophilic sites) of the heteroatoms $\mathrm{N}$ and $\mathrm{O}$. In $\mathrm{G}: \mathrm{C}$, the protonation center at position N7, which corresponds to the most basic site in the neutral molecules, displays a larger region where a significant density of field lines converge. On the other hand, among the four protonation centers found in $\mathrm{A}: \mathrm{U}$, the most basic N3 is the less hidden by the field lines of adjacent electrophilic sites, in particular by those coming from the $\mathrm{H} 2$ nucleus.

The number of these field lines is significantly reduced in the monoprotonated complexes, and they are not observed at all in the diprotonated ones, once the protonation degree increases.

\section{Monoprotonated complexes}

In the case of the protonation at the $\mathrm{NH}_{2}$ group of $A, G$ and $C\left[A\left(N_{2}\right): U, G\left(N_{2}\right): C\right.$, and $\left.G: C\left(N_{2}\right)\right]$, the spontaneous proton transfer observed towards the acceptor oxygen atom of the other molecule can be understood in terms of the disposition of the electric field lines in the neutral complexes $A: U$ and $G: C$. Indeed, the field lines flowing from the electrophilic site situated at the $\mathrm{N}$-nucleus of the $\mathrm{NH}_{2}$ group (for either G, C or A) are ending at the nucleophilic site associated to the free lone pair of the oxygen atom. Hence, a proton bonded to the nitrogen will be under the influence of the force lines that push positives charges from the electrophilic to the nucleophilic sites, leading to the proton transfer between these heteroatoms. 
In the monoprotonated complexes of $\mathrm{G}$ with $\mathrm{C}$, the elongation of the $\mathrm{O6} \cdots \mathrm{H}-\mathrm{N} 4$ hydrogen bond (with respect to the neutral $\mathrm{G}: \mathrm{C}$ system) is observed when protonation takes place at $\mathrm{G}[\mathrm{d}(\mathrm{O} \cdots \mathrm{H})=1.746,1.886$, 1.916 and $2.110 \AA$, for $G: C, G(3): C, G(7): C$ and $G(O 6): C$, respectively] (see Fig. S2 of the Supporting Information material for the second and the latter complexes). The weakening of the pointed HB can be understood in terms of the modification of the electric field lines from the neutral to the three monoprotonated complexes. Indeed, with protonation at N3 or N7, the region initially recovered in G:C by the electric field lines that are flowing from the $\mathrm{H}$-nucleus (electrophilic site in $\mathrm{C}$, belonging to the $\mathrm{NH}_{2}$ group and not directly involved in the $\mathrm{HB}$ interaction) towards the free lone pair of $\mathrm{O} 6$ in $\mathrm{G}$, disappear in both monoprotonated complexes. Consequently, the linking between both molecules around the HB region weakens. In addition, protonation at N7 involves the free lone pair of $\mathrm{O} 6$ in a nucleophilic interaction within the same molecule, polarizing its electron distribution along the corresponding field lines. Inwards the molecule, this polarization acts as an electron withdrawing effect on the acceptor $\mathrm{O} 6$ atom, in particular on its lone pair involved in the HB interaction, weakening its basicity. Consequently, this electronic effect further weakens the HB interaction, leading to a longer $06 \cdots \mathrm{H}$ distance with respect to that found with protonation at N3. On the other hand, protonation at $\mathrm{O} 6$ corresponds to the extreme case of the electron withdrawing effect at the lone pair involved in the HB interaction, making a covalent bond at the free lone pair of $O 6$ in $G: C$ and leading to the longest distance along the series $G: C, G(3): C, G(7): C$ and $G(O 6): C$.

The reverse situation is found with the $A: U$ complexes, where the protonation at $A[A(3): U$ and $A(7): U]$ (see Fig. S2 of the Supporting Information material) shortens the $\mathrm{N} 6-\mathrm{H} \cdots \mathrm{O} 4$ distance $[\mathrm{d}(\mathrm{H} \cdots \mathrm{O} 4)=1.931,1.727$ and $1.710 \AA$, for $A: U, A(3): U$ and $A(7): U$, respectively]. Here, while the electric field lines flowing from the $\mathrm{N} 6-\mathrm{H}$ group towards $\mathrm{O} 4$ are approximately similar in neutral and both monoprotonated complexes, main differences appear with the field lines that coming from the electrophilic site $\mathrm{H} 5$-nucleus in $\mathrm{U}$ are ending at the free lone pair of $\mathrm{O} 4$. Indeed, in the case of the neutral A:U complex, they are further recovering the lone pair, increasing its polarization inwards the molecule and weakening the $\mathrm{HB}$ interaction with respect to both monoprotonated derivatives. Accordingly, comparing with the previous monoprotonated complexes of $G$ with $C$, the $A: U, G(3): C$ and $G(7): C$ systems share a similar electron withdrawing effect on the lone pair involved in the HB interaction, being responsible for the lengthening of the latter. After protonation, effects on inner HBs cannot be easily explained in terms of the electric field lines, as modifications are hidden by their superposition with the contributions of several electrophilic-nucleophilic interactions present in these regions.

As previously pointed out, all the protonated binary complexes are more stable than the corresponding neutral ones, except $\mathrm{G}: \mathrm{C}(\mathrm{O} 2)$. For the neutral complex $\mathrm{G}: \mathrm{C}$, in addition to the main $\mathrm{HB}$ interactions, field lines going from $\mathrm{G}$ to $\mathrm{O} 2$ further link the assembling of both molecules, whereas in $\mathrm{G}: \mathrm{C}(\mathrm{O} 2)$ 
those disappear in the protonation region. This effect significantly weakens the $\mathrm{HB}$ involving $\mathrm{O} 2$ in $\mathrm{G}: \mathrm{C}(\mathrm{O} 2)$ with respect to $\mathrm{G}: \mathrm{C}(\mathrm{d}(\mathrm{H} \cdots \mathrm{O} 2)=1.895$ and $2.660 \AA$ for $\mathrm{G}: \mathrm{C}$ and $\mathrm{G}: \mathrm{C}(\mathrm{O} 2)$, paralleling the electronic origin and the concomitant consequences pointed out with protonation at $\mathrm{O} 6(\mathrm{~d}(\mathrm{H} \cdots \mathrm{O}) \mathrm{6})=2.110 \AA$ for $\mathrm{G}(\mathrm{O} 6): \mathrm{C})$. Among the mono-protonated complexes, similar features are also found with the electric field lines of $A: U(O 2)$ when compared with those of $A: U$, leading to similar observations in their $H B$ distances $(d(H \cdots O 2)=2.698$ and $3.000 \AA$ for $A: U$ and $A: U(O 2)$, respectively). On the other hand, in the case of $A(3): U, A(7): U, A(3): T$, and $A(7): T$, smallest binding energies are found. This trend is brought close to the fact that protonation at N3 or N7 of A does not form further electric field lines linking the molecules of the complexes, while keeping the same HB patterns.

\section{Diprotonated complexes}

Electric field lines linking molecules in neutral and monoprotonated complexes through atoms not involved in $\mathrm{HBs}$ are absent in the diprotonated systems. Thus, as a consequence of their high net positive charge, the electric field lines starting at electrophilic sites in the periphery of the latter point straightforwardly outwards, except in the cases where a nucleophilic site of the same molecule is in the close proximity of an electrophilic site, pulling some of its starting field lines.

As previously indicated, the most stable diprotonated structures are obtained by protonation of the most stable monoprotonated ones. Hence, since the protonation at each base significantly destabilizes the complexes giving rise to a high positive binding energy, only those built from the most stable monoprotonated ones and separating a maximum both protons show up as the least unfavorable diprotonated complexes. Accordingly, the most stable $A(3): U(O 4), A(3): T(O 4)$ and $G(7): C(O 2)$ complexes (see Fig S3 of the S.I. material for the electric field map of the second complex) are respectively formed from $A: U(04), A(3): T$ and $G(7): C$. Thus, the second protonation takes place at a protonation site that is placed as far as possible from the former on other side of the complex, while keeping a maximum of electric field lines linking the bases in the three HB regions.

In general, because of the electrostatic cation $\cdots$ cation repulsion, the HB distances increase when compared to those of the neutral complexes. However, the $\mathrm{N} 6-\mathrm{H} \cdots \mathrm{O} 4$ interaction in $\mathrm{A}(3): \mathrm{U}(\mathrm{O} 2)$ and $\mathrm{A}(7): \mathrm{O}(2)$, and the O6 $\cdots \mathrm{H}-\mathrm{N} 4$ interaction in $\mathrm{G}(3): \mathrm{C}\left(\mathrm{NH}_{2}\right)$ and $\mathrm{G}(7): \mathrm{C}\left(\mathrm{NH}_{2}\right)$, are exceptions (see Fig $\mathrm{S} 3$ of the S.I. material for the electric field maps of the four complexes). Comparing the first two diprotonated complexes with the neutral $\mathrm{A}: \mathrm{U}(\mathrm{d}(\mathrm{H} \cdots \mathrm{O} 4)=1.872,1.872$ and 1.931, $\AA$ for $\mathrm{A}(3): \mathrm{U}(\mathrm{O} 2), \mathrm{A}(7): \mathrm{O}(2)$ and $\mathrm{A}: \mathrm{U}$, respectively), the free lone pair of $\mathrm{O} 4$ in the latter is significantly more involved in the electrostatic interaction with adjacent electrophilic sites of the same molecule ( $\mathrm{H} 5$ and $\mathrm{H} 6$ nuclei). According to previous discussions, this interaction polarizes 
the electron distribution of the acceptor atom $\mathrm{O} 4$ inwards the molecule, weakening the nucleophilic power of its lone pair involved in the HB. The intermolecular electrostatic interaction of the free lone pair of $\mathrm{O} 4$ with both $\mathrm{H}$-nuclei of the $\mathrm{NH}_{2}$ group brings further $\mathrm{HB}$ strengthening in the neutral complex, but it is not able to balance the significant weakening of the HB induced by the intramolecular effect. In the case of the comparison between the second two diprotonated complexes and the neutral $\mathrm{G}: \mathrm{C}(\mathrm{d}(\mathrm{H} \cdots \mathrm{O}) \mathrm{O})=1.538,1.539$ and 1.746, $\AA$ for $G(3): C\left(N_{2}\right), G(7): C\left(N_{2}\right)$ and $G: C$, respectively), two electrostatic effects appear after protonation at the $\mathrm{NH}_{2}$ group. First, it eliminates the electric field lines that coming from the second $\mathrm{H}$ nucleus of the group link the molecules in neutral G:C. Second, the field lines coming from the H-nucleus involved in the $\mathrm{HB}$ further involve the electrostatic basin of 06 . While the first effect weakens the $\mathrm{HB}$ interaction in the diprotonated complexes, the second one strengthens their assembling. In addition, some field lines coming from the nitrogen nucleus of the protonated $\mathrm{NH}_{2}$ group further link the molecules around the $\mathrm{HB}$ region. Altogether, the protonation strengthens the $\mathrm{HB}$ interaction (as observed from the internuclear distances) even in the most unfavorable case $\mathrm{G}(7): \mathrm{C}\left(\mathrm{NH}_{2}\right)$, where the second protonation (at N7) directs some field lines towards the free lone pair of 04 , slightly weakening the basicity of its lone pair involved in the HB. 

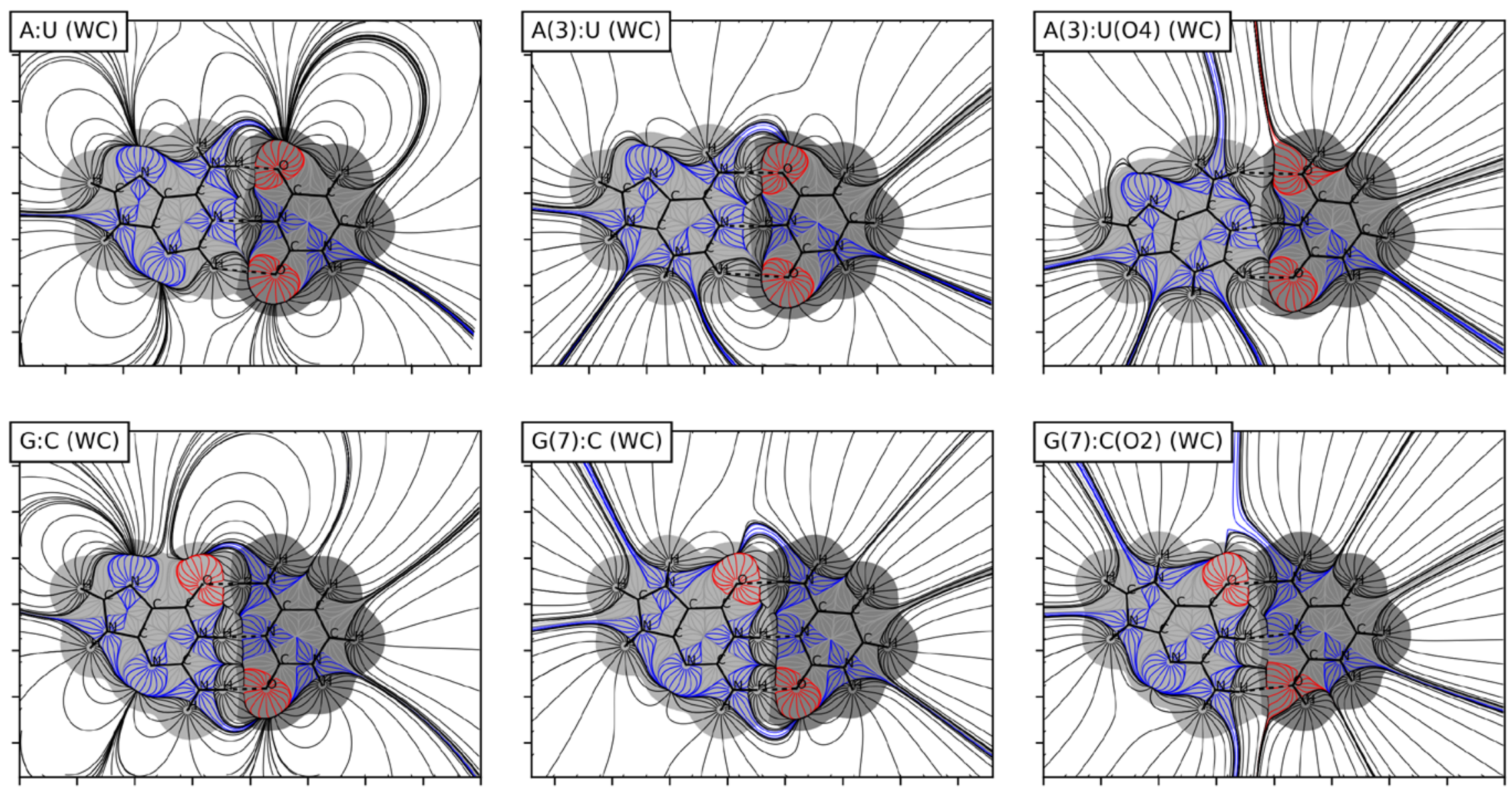

Fig. 5. Electric field trajectories in the $A: U, A(3): U, A(3): U(O 4), G: C, G(7): C$ and $G(7): C(O 2)$ complexes. Electric field lines are colored according to their nuclear origin. The dark shaded regions are the volumes occupied by the uracil or cytosine molecules, whereas light shaded regions correspond to the volumes occupied by the adenine or guanine molecules. The volumes have been calculated from the topology of $\rho(r)$ and are bounded by the isosurface $\rho(r)$ $=0.007$ e $\AA^{-3}$ ( 0.001 a.u. $)$. 


\section{Conclusions}

A DFT theoretical study of the neutral, monoprotonated and diprotonated nucleic acid binary complexes (A:U, $A: T$ and $G: C$ ) in their Watson-Crick conformation has been carried out. Their geometry, configuration energy, electron density distribution and its derived properties, as well as the electric field distribution have been obtained and analyzed. The neutral and monoprotonated binary complexes show negative binding energies, while the diprotonated complexes (mono-protonated in each base) present positive binding energies, although most of them exhibit stable bonding minima. The analysis of the properties of the electron density distribution at bond critical points of HBs (electron density, Laplacian of the electron density, three main curvatures, local electron kinetic $(G)$, potential $(V)$ and total $(H)$ energy density, and ration $|\mathrm{V}| / \mathrm{G})$ indicate that neutral, monoprotonated and diprotonated complexes behave similarly, i.e. the nature of their HBs is independent of the charge of the system. This result further support previous studies with this respect. ${ }^{[30,62]}$

The electric field maps of the binary complexes show a similar profile in the intermolecular regions where hydrogen bonds take place, independently of the system charge. Local electrostatic attractive forces induced by the electric field lines in HB regions are mainly responsible for the observed equilibrium geometries, even in most unfavorable cation...cation complexes. Indeed, in spite of their positive binding energies due to the overall Coulombic repulsion, the electric field lines linking electrophilic and nucleophilic sites in HBs are able to induce restoring forces that maintain these charged complexes at equilibrium geometries, as it has been previously shown up for other anion $\cdots$ anion and cation $\cdots$ cation interactions. ${ }^{[26,28-}$ 30]

In contrast to the observed features in HB regions, electric field lines change significantly in the surrounding of the two bases with the charge in the system. The electrostatic effects induced by these field lines flowing between external parts of the bases superpose to main electrostatic contributions coming from HBs, modulating the effect of electrostatics in the complexes. Thus, as a function of the protonation, the analysis of electric field lines permits to understand how interactions get stronger or weaker by comparing neutral with mono- and di-protonated WC complexes. The increase/decrease of the number of electric field lines flowing from electrophilic sites in one base to nucleophilic sites in the other further strengthens/weakens the assembling in the complex. The elongation/shortening of the HB distance can be brought close to the disappearance/appearance of field lines linking the free lone pair of the HB acceptor to electrophilic sites in the other base, whereas the opposite occurs if electrophilic sites are situated in the same base. In the latter, the appearance of field lines induces a polarization of the electron distribution on 
the acceptor atom inwards its molecular moiety that leads to an electron withdrawing effect, decreasing the basicity of its lone pair involved in the HB and weakening the interaction. On the other hand, electric field lines connecting electrophilic and nucleophilic sites of heteroatoms permit to anticipate proton transfer between them once protonation takes place at the heteroatom bearing the electrophilic site, as force lines push the positively charged proton towards the nucleophilic site.

Although electrostatics have a significant influence in both geometries and energetics of complexes, modifications pointed on single HBs do not always parallel those of the binding energies of the corresponding WC complexes. Several reasons can be invoked, in particular local effects on one of the three HBs assembling the complexes cannot account for the overall energetic modification on the hold system, which is strongly affected by its net charge and the electron distribution through the bases.

\section{Acknowledgments}

This work was supported by the Spanish Ministerio de Economía y Competitividad (Grants CSD2007-00041, ENE2015-63969-C3-3-R, SEV2015-0496 and CTQ2015-63997-C2-2-P), the Catalan Government (Grant PRC 2017SGR-1687), and the Autonomous Community of Madrid (Grant Fotocarbon and S2013/MIT-2841). This work was supported by the French ANR project ANR-17-CE07-0025-01.

\section{Conflict of interest}

The authors declare no conflict of interest

\section{References}

[1] A. Mukherjee, W. D. Sasikala in Chapter One - Drug-DNA Intercalation: From Discovery to the Molecular Mechanism, Vol. 92 (Ed. T. Karabencheva-Christova), Academic Press, 2013, pp.1-62.

[2] A. B. Neto, A. A. Lapis Molecules. 2009, 14.

[3] G. P. Pfeifer in DNA Methylation and Mutation, Vol., John Wiley \& Sons, Ltd, 2001.

[4] V. I. Danilov, T. van Mourik, N. Kurita, H. Wakabayashi, T. Tsukamoto, D. M. Hovorun J. Phys. Chem. A. 2009, 113, 2233-2235.

[5] H. LAl Int. J. Radiat Biol. 1996, 69, 513-521.

[6] R. J. Aitken, L. E. Bennetts, D. Sawyer, A. M. Wiklendt, B. V. King Int. J. Androl. 2005, 28, 171-179.

[7] A. J. Grosovsky, J. G. de Boer, P. J. de Jong, E. A. Drobetsky, B. W. Glickman PNAS. 1988, 85, 185-188.

[8] L. H. Breimer Br J Cancer. 1988, 57, 6-18. 
[9] R. R. Sinder, DNA Structure and function, Academic Press, 1994.

[10] J. Šponer, F. Lankaš, Computational studies of RNA and DNA, Springer, Netherlands, 2006.

[11] E. V. A., W. T. Markiewicz, J. Barciszewski, Chemical Biology of Nucleic Acids, Springer, 2014.

[12] E. Ennifar, Nucleic Acid Crystallography, Springer, 2015.

[13] K. Nakatani, Y. Tor, Modified Nucleic Acids, Springer, 2016.

[14] L. Rodríguez-Santiago, M. Noguera, J. Bertran, M. Sodupe in Hydrogen Bonding and Proton Transfer in ionized DNA Base Pairs, Amino Acids and Peptides, Vol., Wiley-VCH Verlag GmbH \& Co. KGaA, 2010, pp.219243.

[15] J. L. Asensio, A. N. Lane, J. Dhesi, S. Bergqvist, T. Brown J. Mol. Biol. 1998, 275, 811-822.

[16] P. C. Bevilacqua in Chapter 2 Proton Transfer in Ribozyme Catalysis, Vol., The Royal Society of Chemistry, 2007, pp.11-36.

[17] J. L. Wilcox, A. K. Ahluwalia, P. C. Bevilacqua Acc. Chem. Res. 2011, 44, 1270-1279.

[18] E. A. Frankel, P. C. Bevilacqua Biochemistry. 2018, 57, 483-488.

[19] J. L. Wilcox, P. C. Bevilacqua J. Am. Chem. Soc. 2013, 135, 7390-7393.

[20] L. Yang, Z. Zhong, C. Tong, H. Jia, Y. Liu, G. Chen J. Am. Chem. Soc. 2018, 140, 8172-8184.

[21] J. L. Wilcox, P. C. Bevilacqua Biochemistry. 2013, 52, 7470-7476.

[22] U. A. Budniak, P. M. Dominiak Acta Crystallographica Section C. 2018, 74, 108-112.

[23] P. Kumar, M. K. Cabaj, A. Pazio, P. M. Dominiak IUCrJ. 2018, 5, 449-469.

[24] S. R. Kass J. Am. Chem. Soc. 2005, 127, 13098-13099.

[25] L. Feketeova, R. A. J. O'Hair Chem. Commun. 2008, 4942-4944.

[26] I. Mata, I. Alkorta, E. Molins, E. Espinosa Chemphyschem. 2012, 13, 1421-1424.

[27] A. Shokri, M. Ramezani, A. Fattahi, S. R. Kass J. Phys. Chem. A. 2013, 117, 9252-9258.

[28] I. Mata, I. Alkorta, E. Molins, E. Espinosa Chem. Phys. Lett. 2013, 555, 106-109.

[29] I. Mata, E. Molins, I. Alkorta, E. Espinosa J. Phys. Chem. A. 2015, 119, 183-194.

[30] I. Alkorta, I. Mata, E. Molins, E. Espinosa Chem. Eur. J. 2016, 22, 9226-9234.

[31] D. Quiñonero, I. Alkorta, J. Elguero PCCP. 2016, 18, 27939-27950.

[32] S. M. Chalanchi, I. Alkorta, J. Elguero, D. Quiñonero ChemPhysChem. 2017, 18, 3462-3468.

[33] R. Prohens, A. Portell, M. Font-Bardia, A. Bauza, A. Frontera Chem. Commun. 2018, 54, 1841-1844

[34] M. A. Carvajal, I. Garcia-Yoldi, J. J. Novoa Theochem. 2005, 727, 181-189.

[35] P. A. Gale, K. Navakhun, S. Camiolo, M. E. Light, M. B. Hursthouse J. Am. Chem. Soc. 2002, 124, 1122811229.

[36] A. S. R. Chesman, J. L. Hodgson, E. I. Izgorodina, A. Urbatsch, D. R. Turner, G. B. Deacon, S. R. Batten Cryst. Growth Des. 2014, 14, 1922-1932.

[37] M. Vazdar, J. Vymetal, J. Heyda, J. Vondrasek, P. Jungwirth J. Phys. Chem. A. 2011, 115, 11193-11201.

[38] G. Wang, Z. Chen, Z. Xu, J. Wang, Y. Yang, T. Cai, J. Shi, W. Zhu J. Phys. Chem. B. 2016, 120, 610-620.

[39] F. Weinhold, R. A. Klein Angew. Chem. Int. Ed. 2014, 53, 11214-11217.

[40] F. Weinhold Inorg. Chem. 2018, 57, 2035-2044.

[41] G. Frenking, G. F. Caramori Angew. Chem. Int. Ed. 2015, 54, 2596-2599.

[42] F. Weinhold, R. A. Klein Angew. Chem. Int. Ed. 2015, 54, 2600-2602.

[43] C. Wang, Y. Fu, L. Zhang, D. Danovich, S. Shaik, Y. Mo J. Comput. Chem. 2018, 39, 481-487.

[44] Y. Zhao, D. Truhlar Theor. Chem. Acc. 2008, 120, 215-241.

[45] T. H. Dunning J. Chem. Phys. . 1989, 90, 1007-1023.

[46] J. A. Plumley, J. J. Dannenberg J. Comput. Chem. 2011, 32, 1519-1527.

[47] M. Walker, A. J. A. Harvey, A. Sen, C. E. H. Dessent J. Phys. Chem. A. 2013, 117, 12590-12600.

[48] Y. Liu, J. Zhao, F. Li, Z. Chen J. Comput. Chem. 2013, 34, 121-131.

[49] J. Gu, J. Wang, J. Leszczynski, Y. Xie, H. F. Schaefer Chem. Phys. Lett. 2008, 459, 164-166.

[50] J. Gu, J. Wang, J. Leszczynski Chem. Phys. Lett. 2011, 512, 108-112.

[51] C. A. Morgado, P. Jurečka, D. Svozil, P. Hobza, J. Šponer PCCP. 2010, 12, 3522-3534.

[52] M. J. Frisch, G. W. Trucks, H. B. Schlegel, G. E. Scuseria, M. A. Robb, J. R. Cheeseman, G. Scalmani, V. Barone, B. Mennucci, G. A. Petersson, H. Nakatsuji, M. Caricato, X. Li, H. P. Hratchian, A. F. Izmaylov, J. Bloino, G. Zheng, J. L. Sonnenberg, M. Hada, M. Ehara, K. Toyota, R. Fukuda, J. Hasegawa, M. Ishida, T. 
Nakajima, Y. Honda, O. Kitao, H. Nakai, T. Vreven, J. A. Montgomery Jr., J. E. Peralta, F. Ogliaro, M. J. Bearpark, J. Heyd, E. N. Brothers, K. N. Kudin, V. N. Staroverov, R. Kobayashi, J. Normand, K. Raghavachari, A. P. Rendell, J. C. Burant, S. S. Iyengar, J. Tomasi, M. Cossi, N. Rega, N. J. Millam, M. Klene, J. E. Knox, J. B. Cross, V. Bakken, C. Adamo, J. Jaramillo, R. Gomperts, R. E. Stratmann, O. Yazyev, A. J. Austin, R. Cammi, C. Pomelli, J. W. Ochterski, R. L. Martin, K. Morokuma, V. G. Zakrzewski, G. A. Voth, P. Salvador, J. J. Dannenberg, S. Dapprich, A. D. Daniels, Ö. Farkas, J. B. Foresman, J. V. Ortiz, J. Cioslowski, D. J. Fox in Gaussian 09, Rev. D.01, Gaussian, Inc., City, 2009.

[53] R. F. W. Bader, Atoms in Molecules: A Quantum Theory, Clarendon Press, Oxford, 1990.

[54] P. L. A. Popelier, Atoms In Molecules. An introduction, Prentice Hall, Harlow, England, 2000.

[55] T. A. Keith in AIMAll, TK Gristmill Software, City, 2014.11.23 Version (aim.tkgristmill.com).

[56] J. D. Hunter Comput. Sci. Eng. 2007, 9, 90-95.

[57] Y. Podolyan, L. Gorb, J. Leszczynski J. Phys. Chem. A. 2000, 104, 7346-7352.

[58] J. Ran, P. Hobza J. Phys. Chem. B. 2009, 113, 2933-2936.

[59] M. Kabeláč, P. Hobza J. Phys. Chem. B. 2001, 105, 5804-5817.

[60] G. Varani, W. H. McClain EMBO reports. 2000, 1, 18-23.

[61] E. Espinosa, I. Alkorta, J. Elguero, E. Molins J. Chem. Phys. . 2002, 117, 5529-5542.

[62] I. Mata, I. Alkorta, E. Molins, E. Espinosa Chem. Eur. J. 2010, 16, 2442-2452.

[63] R. F. W. Bader, P. M. Beddall J. Chem. Phys. . 1972, 56, 3320-3329.

[64] R. F. W. Bader, M. T. Carroll, J. R. Cheeseman, C. Chang J. Am. Chem. Soc. 1987, 109, 7968-7979.

[65] I. Mata, E. Molins, E. Espinosa J. Phys. Chem. A. 2007, 111, 9859-9870.

[66] I. Mata, E. Molins, I. Alkorta, E. Espinosa J. Phys. Chem. A. 2007, 111, 6425-6433. 